\title{
The WHO Adult ADHD Self-Report Scale: Reliability and Validity of the Korean Version
}

\author{
Ji-Hae Kim, Eun-Ho Lee and Yoo-Sook Joung ${ }^{凶}$ \\ Department of Psychiatry, Samsung Medical Center, Sungkyunkwan University School of Medicine, Seoul, Republic of Korea
}

Objective A self-report scale of adult attention-deficit/hyperactivity disorder, the World Health Organization (WHO) Adult ADHD Self-Report Scale (ASRS) was developed and demonstrated good psychometric properties. The purpose of the present study is to investigate the psychometric properties of the ASRS in Korean samples.

Methods The ASRS includes 18 questions regarding the frequency of recent DSM-IV Criterion A symptoms of adult ADHD. We examined the factor structure, internal consistency, and convergent validity of the ASRS in Korean samples.

Results The ASRS demonstrated good internal consistency and test-retest reliability. Correlations between the ASRS and other adult ADHD measures were high, providing evidence of convergent validity. A subsequent exploratory factor analysis indicated that a twofactor solution provided the best fit.

Conclusion It is expected that this scale would be helpful in clinical settings and research in Korea.

Psychiatry Investig 2013;10:41-46

Key Words ASRS, Adult ADHD, Scale, Psychometric properties, Korean.

\section{INTRODUCTION}

Attention deficit/hyperactive disorder (ADHD) is one of the most common psychiatric disorders among children and adolescents. ${ }^{1}$ ADHD was thought to be exclusively a childhood disorder; now, it is recognized that this disorder frequently persists into adulthood. It currently afflicts approximately $4-5 \%$ of the United States (US) adult population. ${ }^{2-5}$ ADHD can cause significant employment, marital, social, and educational impairments. However, adult ADHD is vastly under-diagnosed and under-recognized in adults, which underscores the critical need for valid screening tools. ${ }^{6}$ The majority of the rating scales are designed to assess the eighteen diagnostic criteria of DSM-IV. ${ }^{7}$ Some rating scales check for additional psychopathological symptoms. The Conners Adult ADHD Rating Scales (CAARS $)^{8}$ have found general acceptance. They in-

Received: May 8, 2012 Revised: August 27, 2012

Accepted: October 9, 2012 Available online: January 24, 2013

$\triangle$ Correspondence: Yoo-Sook Joung, MD, PhD

Department of Psychiatry, Samsung Medical Center, Sungkyunkwan University School of Medicine, 50 Irwon-dong, Gangnam-gu, Seoul 135-710, Republic of Korea

Tel: +82-2-3410-0930, Fax: +82-2-3410-0050, E-mail: yschoung@skku.edu

(a) This is an Open Access article distributed under the terms of the Creative Commons Attribution Non-Commercial License (http://creativecommons.org/licenses/bync/3.0) which permits unrestricted non-commercial use, distribution, and reproduction in any medium, provided the original work is properly cited. clude a set of self-report (CAARS-SR) and observer-report scales (CAARS-OR). The CAARS allow not only the calculation of DSM-IV oriented inattention, impulsivity and hyperactivity scores, but also measures of emotional lability and problems with self-concept. In comparison to the CAARS, the Current Symptoms Scales (CSS-OR and CSS-SR) focus exclusively on the DSM-IV defined psychopathology. Although a number of measures exist to screen for adult $\mathrm{ADHD},{ }^{10}$ one of the most promising is the screening scale used for the US national survey, the World Health Organization's Adult ADHD Self-Report Scale v1.1 Symptom Checklist (ASRS). ${ }^{6}$ The ASRS is a DSM-IV-based measure, which includes 18 questions regarding the frequency of recent DSM-IV Criterion A symptoms of adult ADHD. The wording of questions in the ASRS, worded slightly different from the ADHD Rating Scale for children, is designed to collect information regarding ADHD symptoms in the context of adulthood rather than childhood, providing a context for symptoms to which adults can relate. For example, references to "play" and "schoolwork" have been replaced by "work" and "boring or difficult project." The selfreport version of the ASRS was developed and proved to be a reliable format for use in clinical and research settings. It demonstrated good psychometric properties and is also used for epidemiology purposes in the US. ${ }^{11}$ The scale has been trans- 
lated into several different languages and has been widely used in recent internationally epidemiological studies. ${ }^{12}$

Thus, the goal of the present study was to translate and validate the cross-cultural utility of the ASRS in Korean samples.

\section{METHODS}

\section{Development of the Korean versions of the WHO adult ADHD Self-Report Scale (ASRS)}

The ASRS included questions regarding the frequency of all 18 DSM-IV Criterion A symptoms of adult ADHD. Each ASRS question asks respondents how often a particular symptom of ADHD has occurred to them over the past six months on a five-point response scale ranging from never (0), rarely (1), sometimes (2), often (3), to very often (4). The total scores range from 0 to 72 .

The ASRS is part of the revised version of the WHO Composite International Diagnostic Interview (CIDI) developed for the World Mental Health (WMH) surveys (WMH-CIDI). As such, the ASRS is copyrighted by the WHO. Under WHO's approval, we translated the instrument based on the standard WMH-CIDI protocol. Our cultural adaptation procedures includes, an initial forward version, a summary of recommendation by the expert panel, a back-translation, modifications agreed to during the international harmonization; a summary of problems found during the pre-testing of the questionnaire and the modifications proposed; and the final version. The process documents and final version are then sent to and reviewed by Dr. Ronald C. Kessler, the chair of the WMH-CIDI advisory committee. ${ }^{6}$

\section{Sample and procedures}

The study population comprised a community sample of 205 individuals from the Kyoung-Ki District and Seoul Metropolitan areas. The participants were solicited via advertisements requesting volunteers for various psychological assessments. No data are available on the clinical history of these participants. The participants ranged in age from 18 to 38 years and 119 of them $(58 \%)$ were females (Mean age $=22.28$ years, $\mathrm{SD}=3.60$ ). The participants were administered a battery of questionnaires, which took a total of approximately 30 minutes to complete. The Institutional Review Board (IRB) of Samsung Medical Center approved this study, and all participants were safeguarded through informed consent and confidentiality.

\section{Measures}

To address the properties of the measure in terms of convergent and divergent validity, several other measures were included, in addition to the ASRS. Convergent validity was assessed by comparing the ASRS with the Conners Adult ADHD Rating Scale, a known and validated questionnaire measuring similar concepts. The Conners Adult ADHD Rating Scale (CAARS) is a 62 item measure of adult ADHD symptoms. ${ }^{8}$ We administered a Korean version of the CAARS, ${ }^{13}$ which has demonstrated good psychometric properties. The internal consistency coefficient of the Korean version of the CAARS has been reported to be 0.91 . Beck Depression Inventory, ${ }^{14,15}$ and the Spielberger State-Trait Anxiety Inventory ${ }^{16}$

Table 1. The demographic and psychological characteristics $(\mathrm{N}=205)$

\begin{tabular}{|c|c|c|c|c|c|}
\hline & \multicolumn{2}{|c|}{ Male $(\mathrm{N}=85)$} & \multicolumn{2}{|c|}{ Female $(\mathrm{N}=120)$} & \multirow{2}{*}{$\mathrm{t}(203)$} \\
\hline & M & SD & M & SD & \\
\hline Age (year) & 22.21 & 2.62 & 22.33 & 4.19 & -0.232 \\
\hline ASRS & 27.31 & 10.94 & 25.97 & 9.37 & 0.941 \\
\hline \multicolumn{6}{|l|}{ CAARS } \\
\hline Inattention/Memory problems & 12.06 & 5.72 & 13.50 & 5.62 & -1.806 \\
\hline Hyperactivity/Restlessness & 14.09 & 5.64 & 12.40 & 6.17 & $2.005^{*}$ \\
\hline Impulsivity/Emotional lability & 11.05 & 6.79 & 12.90 & 6.67 & -1.948 \\
\hline Problems with self-concept & 7.12 & 4.52 & 7.96 & 4.28 & -1.358 \\
\hline DSM-IV inattentive symptoms & 8.14 & 4.89 & 8.82 & 4.71 & -1.010 \\
\hline DSM-IV hyperactivity-impulsive symptoms & 7.37 & 4.12 & 7.34 & 4.10 & 0.062 \\
\hline DSM-IV total ADHD symptoms & 15.51 & 8.32 & 16.16 & 8.09 & -0.559 \\
\hline ADHD index & 12.63 & 5.97 & 13.05 & 5.59 & -0.519 \\
\hline BDI & 9.45 & 7.95 & 10.51 & 7.36 & -0.983 \\
\hline STAI-S & 41.71 & 12.12 & 42.41 & 11.06 & -0.431 \\
\hline STAI-T & 42.50 & 11.99 & 45.65 & 10.34 & $-2.010^{*}$ \\
\hline
\end{tabular}

${ }^{*} \mathrm{p}<0.05$. ASRS: Adult ADHD Self-Report Scale, BDI: Beck Depression Inventory, STAI-S: The Spielberger State-Trait Anxiety InventoryState, STAI-T: The Spielberger State-Trait Anxiety Inventory-Trait, CAARS: The Conners Adult ADHD Rating Scales 
which have been widely used for self-report to measure depressive and anxiety symptoms, were included.

\section{Statistical analyses}

The statistical analyses for the reliability and validity of the ASRS were performed using SPSS for Windows (Version 17.0; SPSS, Chicago, IL, USA). The internal consistency was estimated by using Cronbach's a coefficient. Alpha coefficients of 0.7 or higher were considered acceptable. For the test-retest reliability, forty-one participants received the ASRS again after a two-week interval. Pearson correlation coefficients were computed to analyze convergent and divergent validity between the ASRS and the CAARS, the BDI, the STAI-S, and the STAI-

Table 2. Mean, standard deviation, and correlation of each ASRS item with the sum of the other items and internal consistency if the item is deleted $(\mathrm{N}=205)$

\begin{tabular}{rcccc}
\hline Items & Mean & SD & $\begin{array}{c}\text { Corrected } \\
\text { item-total } \\
\text { correlation }\end{array}$ & $\begin{array}{c}\text { Alpha if item } \\
\text { deleted }\end{array}$ \\
\hline 1 & 1.60 & 0.93 & 0.483 & 0.880 \\
2 & 1.35 & 0.91 & 0.581 & 0.876 \\
3 & 1.37 & 0.94 & 0.512 & 0.879 \\
4 & 2.33 & 0.91 & 0.551 & 0.878 \\
5 & 2.27 & 1.15 & 0.399 & 0.884 \\
6 & 1.14 & 1.02 & 0.417 & 0.882 \\
7 & 1.71 & 0.86 & 0.526 & 0.878 \\
8 & 2.01 & 1.01 & 0.540 & 0.878 \\
9 & 1.04 & 0.91 & 0.432 & 0.881 \\
10 & 1.87 & 1.11 & 0.481 & 0.880 \\
11 & 2.07 & 0.88 & 0.516 & 0.879 \\
12 & 0.81 & 0.87 & 0.607 & 0.876 \\
13 & 1.52 & 1.02 & 0.639 & 0.874 \\
14 & 1.11 & 1.03 & 0.556 & 0.877 \\
15 & 1.27 & 0.99 & 0.500 & 0.879 \\
16 & 1.33 & 0.93 & 0.476 & 0.880 \\
17 & 0.92 & 0.98 & 0.529 & 0.878 \\
18 & 0.82 & 0.81 & 0.561 & 0.878 \\
\hline ASRS Adult & ADHD Self & &
\end{tabular}

ASRS: Adult ADHD Self-Report Scale
T. Convergent validity was considered to be demonstrated when correlations between compatible dimensions were significantly higher than those between theoretically different dimensions and were of a reasonable magnitude. Correlation coefficients between 0.1 and 0.3 were considered low, those between 0.31 and 0.5 were moderate, and those over 0.5 were considered high. ${ }^{17}$

Prior to conducting factor analysis, data were evaluated for possible departures from normality. The Kolomogorov-Smirnov test was used to examine skewness and kurtosis of the scale (skewness $=0.41$ and kurtosis $=0.61$ ). There were no indicators that departed from normal distribution. The latent variable analysis was performed using the principal-axis factor analysis.

\section{RESULTS}

There are no gender differences in the ASRS, the BDI and the STAI-S. Differences by gender were found only in the STAI-T and the Hyperactivity/Restlessness subscale of the CAARS (Table 1).

\section{Reliability}

The mean scores of items, the standard deviation, and the corrected item-total correlation, i.e., the correlation of each item with the sum of the remaining items, are shown in Table 2. Assessment of the internal consistency of the ASRS yielded an overall Cronbach's $\alpha$ of .885 for the entire scale. Two week test-retest reliability of the ASRS was $0.878(\mathrm{p}<0.001)$.

\section{Convergent and divergent validity}

Table 3 shows the results of the convergent validity analysis. The ASRS and all of the CAARS subscales showed a high level of correlation. Among the CAARS subscales, Total ADHD Symptoms $(r=0.784)$ and Inattentive Symptoms $(r=0.774)$ displayed higher correlations than the other scales. The BDI $(r=$ $0.372)$ and the STAI-S $(r=0.479)$ demonstrated a moderate level of correlation, but the STAI-T $(r=0.565)$ revealed a high level of correlation with the ASRS.

Table 3. Correlations between the ASRS with the CAARS Subscales $(\mathrm{N}=205)$

\begin{tabular}{|c|c|c|c|c|c|c|c|c|c|c|c|}
\hline \multicolumn{12}{|c|}{ CAARS } \\
\hline & $\begin{array}{l}\text { Inattention/ } \\
\text { Memory }\end{array}$ & $\begin{array}{c}\text { Hyperactivity/ } \\
\text { Restlessness }\end{array}$ & $\begin{array}{c}\text { Impulsivity/ } \\
\text { Emotional } \\
\text { Liability }\end{array}$ & $\begin{array}{l}\text { Problems } \\
\text { with Self- } \\
\text { Concept }\end{array}$ & $\begin{array}{l}\text { DSM-IV } \\
\text { Inattentive } \\
\text { Symptoms }\end{array}$ & $\begin{array}{c}\text { DSM-IV } \\
\text { Hyperactivity- } \\
\text { Impulsive } \\
\text { Symptoms }\end{array}$ & $\begin{array}{c}\text { DSM-IV } \\
\text { Total } \\
\text { ADHD } \\
\text { Symptoms } \\
\end{array}$ & $\begin{array}{l}\text { ADHD } \\
\text { Index }\end{array}$ & BDI & STAI-S & STAI-T \\
\hline ASRS & $0.675^{* *}$ & $0.585^{* *}$ & $0.679^{* *}$ & $0.532^{* *}$ & $0.774^{* *}$ & $0.659^{* *}$ & $0.784^{* *}$ & $0.685^{* *}$ & $0.372^{* *}$ & $0.479^{* *}$ & $0.565^{* *}$ \\
\hline
\end{tabular}




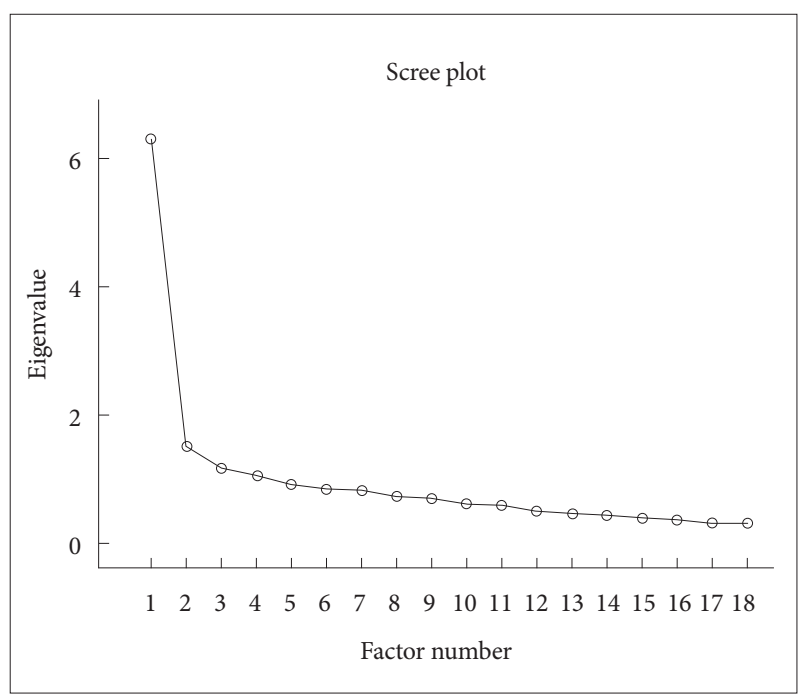

Figure 1. Scree plot.

\section{Construct validity}

The factor structure of the ASRS was examined using the principal-axis factor analysis. Factors were rotated using a direct oblimin rotation $(\delta=0)$. The results of the exploratory factor analysis revealed four factors with eigenvalues of $>1$, but two factors were selected by a scree test (Figure 1), along with coherence and interpretability (Table 4 ).

The 2 -factor solution yielded and explained $37.19 \%$ of the total variance. Factor 1 consisted of 14 items ("how often do you have trouble wrapping up the final details of a project, once the challenging parts have been done?" "how often do you have difficulty getting things in order when you have to do a task that requires organization?" "how often do you have problems remembering appointments or obligations?" "when you have a task that requires a lot of thought, how often do you avoid or delay getting started?" "how often do you fidget

Table 4. Item loadings for the four factors of the ASRS from the exploratory factor analysis

\begin{tabular}{|c|c|c|c|}
\hline & Factor I & Factor II & \\
\hline $\begin{array}{l}\text { 1. How often do you have trouble wrapping up the final details of a project, } \\
\text { once the challenging parts have been done? }\end{array}$ & 0.418 & -0.160 & $\bar{A}$ \\
\hline $\begin{array}{l}\text { 2. How often do you have difficulty getting things in order when you have to do a task } \\
\text { that requires organization? }\end{array}$ & 0.623 & -0.36 & A \\
\hline 3. How often do you have problems remembering appointments or obligations? & 0.385 & -0.234 & A \\
\hline $\begin{array}{l}\text { 4. When you have a task that requires a lot of thought, how often do you avoid or delay } \\
\text { getting started? }\end{array}$ & 0.517 & -0.134 & A \\
\hline $\begin{array}{l}\text { 5. How often do you fidget or squirm with your hands or feet when you have to sit down } \\
\text { for a long time? }\end{array}$ & 0.489 & 0.040 & $\mathrm{~B}$ \\
\hline $\begin{array}{l}\text { 6. How often do you feel overly active and compelled to do things, like you were driven } \\
\text { by a motor? }\end{array}$ & 0.400 & -0.097 & $\mathrm{~B}$ \\
\hline $\begin{array}{l}\text { 7. How often do you make careless mistakes when you have to work on a boring } \\
\text { or difficult project? }\end{array}$ & 0.761 & 0.212 & A \\
\hline $\begin{array}{l}\text { 8. How often do you have difficulty keeping your attention when you are doing boring } \\
\text { or repetitive work? }\end{array}$ & 0.752 & 0.172 & A \\
\hline $\begin{array}{l}\text { 9. How often do you have difficulty concentrating on what people say to you, } \\
\text { even when they are speaking to you directly? }\end{array}$ & 0.537 & 0.075 & A \\
\hline 10. How often do you misplace or have difficulty finding things at home or at work? & 0.471 & -0.110 & A \\
\hline 11. How often are you distracted by activity or noise around you? & 0.524 & -0.074 & A \\
\hline $\begin{array}{l}\text { 12. How often do you leave your seat in meetings or other situations in which you are } \\
\text { expected to remain seated? }\end{array}$ & 0.495 & -0.239 & $\mathrm{~B}$ \\
\hline 13. How often do you feel restless or fidgety? & 0.550 & -0.216 & B \\
\hline 14. How often do you have difficulty unwinding and relaxing when you have time to yourself? & 0.530 & -0.130 & $\mathrm{~B}$ \\
\hline 15. How often do you find yourself talking too much when you are in social situations? & 0.204 & -0.456 & $\mathrm{~B}$ \\
\hline $\begin{array}{l}\text { 16. When you're in a conversation, how often do you find yourself finishing the sentences } \\
\text { of the people you are talking to, before they can finish them themselves? }\end{array}$ & -0.107 & -0.887 & $\mathrm{~B}$ \\
\hline $\begin{array}{l}\text { 17. How often do you have difficulty waiting your turn in situations when turn taking } \\
\text { is required? }\end{array}$ & 0.259 & -0.431 & $\mathrm{~B}$ \\
\hline 18. How often do you interrupt others when they are busy? & 0.210 & -0.575 & $\mathrm{~B}$ \\
\hline
\end{tabular}

A: Inattention, B: Hyperactivity and Impulsivity. ASRS: Adult ADHD Self-Report Scale 
or squirm with your hands or feet when you have to sit down for a long time?" "how often do you feel overly active and compelled to do things, like you were driven by a motor?" "how often do you make careless mistakes when you have to work on a boring or difficult project?" "how often do you have difficulty keeping your attention when you are doing boring or repetitive work?" "how often do you have difficulty concentrating on what people say to you, even when they are speaking to you directly?" "how often do you misplace or have difficulty finding things at home or at work?" "how often are you distracted by activity or noise around you?" "how often do you leave your seat in meetings or other situations in which you are expected to remain seated?" "how often do you feel restless or fidgety?" and "how often do you have difficulty unwinding and relaxing when you have time to yourself?") and accounted for $31.58 \%$ of the total variance. This factor was labeled "inattention/hyperactivity."

Factor 2 included 4 items ("how often do you find yourself talking too much when you are in social situations?" "when you're in a conversation, how often do you find yourself finishing the sentences of the people you are talking to, before they can finish them themselves?" "how often do you have difficulty waiting your turn in situations when turn taking is required?" "how often do you interrupt others when they are busy?") and accounted for $5.24 \%$ of the total variance. We named this factor "impulsivity."

\section{DISCUSSION}

The present study was conducted to examine the psychometric properties of the ASRS in Korean samples. Classical psychometric analysis confirmed the scale's ability for sound measurement with sufficient psychometric properties. The internal consistency of the total item and 2-week test-retest reliability were high.

We analyzed the concurrent validity by correlating the ASRS with the CAARS, a similar instrument to assess the adult ADHD. The ASRS was highly correlated with the CAARS for all subscales. The BDI, the STAI-S showed only moderate level of correlations with the ASRS. This refers to a satisfying convergent validity. However, the correlation between the ASRS and the STAI-T were higher than we expected, but this result may be due to the high comorbidity between adult ADHD and anxiety disorders. ${ }^{18,19}$

Results from our exploratory factor analysis suggested that a two-factor solution provided a suitable fit for the present data. The two-factor consisted of 'inattention/hyperactivity' and "impulsivity". Our finding is in line with previous research conducted in Spain for substance addiction group, ${ }^{20}$ but given the paucity of study reporting the factor structure, more research using diverse population will be needed to clarify the internal structure of the ASRS.

There were no gender differences in the ASRS. This result is contrary to some previous reports, which found significantly higher prevalence of ADHD in males, ${ }^{21}$ but is consistent with findings from another recent study of a large representative population sample. ${ }^{22,23}$ This difference may be due to the fact that we report ADHD symptoms and not clinically diagnosed cases. However, gender differences in ADHD prevalence is known to be more extreme in pediatric samples compared to adolescent and adult samples. ${ }^{22}$ It has been reported that since childhood referrals are initiated by parents and teachers, girls without the hyperactivity component of ADHD are less likely to be clinically diagnosed. ${ }^{24}$ In epidemiological samples male patients outnumber females by a ratio of 2-3 to 1 in childhood. In adults the gender ratio tends to be more equal. ${ }^{25}$

There are several limitations in this study. First, the majority of our sample was taken from a young population. Therefore, it should be noted that this findings may not be generalized to other sample such as an aged group, and replication should involve a more representative sample from the general population, including a patient group with adult ADHD. Second, all data were obtained from respondents rather than from informants. Methodological studies comparing adult self-reports versus informant reports of ADHD symptoms generally display the same pattern of disagreement as in studies of child self-reports versus informant reports ${ }^{26}$; namely, that informants report higher symptoms than respondents. ${ }^{27,28}$ This suggests that both the clinical interviews and the ASRS results might be conservative. It is important to note, however, that the one adult self-versus informant ADHD symptom comparison study that was carried out in a non-clinical sample found fairly strong associations between the two reports and no self-informant differences in symptom severity were reported. ${ }^{6,29}$ Third, all measures for the concurrent validity used in our study were self-report questionnaires, which might have inflated the relationships among the study variables. Further validity studies must be done using the clinical interview as the gold standard. Lastly, the ASRS screener should be investigated further. The ASRS includes 18 questions regarding the frequency of recent DSM-IV Criterion A symptoms of adult ADHD. The ASRS screener consists of six of these 18 questions based on a stepwise logistic regression to optimize concordance with the clinical classification. ${ }^{6}$ The sixquestion ASRS screener, in comparison, appears to hold more promise than the full ASRS for clinical screening purposes. Thus, the six-question ASRS screener should be investigated more rigorously. ${ }^{6}$

In summary, the Korean ASRS showed good reliability and satisfactory validity. This research suggests that the ASRS ap- 
pears to be a promising measure of Adult ADHD. The ASRS was determined to be composed of internally consistent and psychometrically sound items.

\section{Acknowledgments}

The current version of the Adult ADHD Self-Report Scale symptom checklist is copyrighted by the World Health Organization and is available at http://webdoc.nyumc.org/nyumc_d6/files/psych_adhd_checklist.pdf at no cost

This project was funded by Janssen Korea Limited (Local Protocol No.: CON-KOR-9023)

\section{REFERENCES}

1. Biederman J, Faraone SV. Attention deficit hyperactivity disorder: a worldwide concern. J Nerv Ment Dis 2004;192:453-454.

2. Faraone SV, Sergeant J, Gillberg C, Biederman J. The worldwide prevalence of ADHD: is it an American condition? World Psychiatry 2003;2: 104-113.

3. Murphy K, Barkley RA. Attention deficit hyperactivity disorder adults: comorbidities and adaptive impairments. Compr Psychiatry 1996;37: 393-401.

4. Torralva T, Gleichgerrcht E, Lischinsky A, Roca M, Manes F. "Ecological" and Highly Demanding Executive Tasks Detect Real-Life Deficits in High-Functioning Adult ADHD Patients. J Atten Disord 2012 inpress.

5. Wender PH, Wolf LE, Wasserstein J. Adults with ADHD. An overview. Ann N Y Acad Sci 2001;931:1-16.

6. Kessler RC, Adler L, Ames M, Demler O, Faraone S, Hiripi E, et al. The World Health Organization Adult ADHD Self-Report Scale (ASRS): a short screening scale for use in the general population. Psychol Med 2005;35:245-256.

7. Kim Y, Jung HY, Roh S. Rating scales for attention-deficit hyperactivity disorders in adults. J Korean Acad Child Adolesc Psychiatry 2010;21: 11-18.

8. Conners CK, Erhardt D, Sparrow E. Conners' Adult ADHD Rating Scales: Technical Manual. New York: Multi Health System; 1999.

9. Barkley RA, Murphy KR. Attention-Deficit Hyperactivity Disorder: A Clinical Workbook. NY: Guilford Press; 1998.

10. Belendiuk KA, Clarke TL, Chronis AM, Raggi VL. Assessing the concordance of measures used to diagnose adult ADHD. J Atten Disord 2007;10:276-287.

11. Adler LA, Spencer T, Faraone SV, Kessler RC, Howes MJ, Biederman J, et al. Validity of pilot Adult ADHD Self- Report Scale (ASRS) to Rate Adult ADHD symptoms. Ann Clin Psychiatry 2006;18:145-148.

12. Yeh CB, Gau SS, Kessler RC, Wu YY. Psychometric properties of the Chinese version of the adult ADHD Self-report Scale. Int J Methods Psychiatr Res 2008; 17:45-54.

13. Kim H, Lee J, Cho S, Lee IS, Kim JH. A preliminary study on reliability and validity of the Conners Adult ADHD Rating Scales-Korean ver- sion in college students. Korean J Clin Psychol 2005;24:171-185.

14. Beck AT, Steer RA. Internal consistencies of the original and revised Beck Depression Inventory. J Clin Psychol 1984;40:1365-1367.

15. Lee YS, Song JY. A study of reliability and validity of the BDI, the SDS, and MMPI-D scale. Korean J Clin Psychol 1991;10:98-113.

16. Spielberger CD, Gorsuch RL. Manual for the State-Trait Anxiety Inventory (Form Y) : "Self-Evaluation Questionnaire". Palo Alto, CA: Consulting Psychologists Press; 1983.

17. Bortz J, Döring N. Forschungsmethoden und evaluation. Aufl: Springer Berlin; 1995.

18. Klassen LJ, Katzman MA, Chokka P. Adult ADHD and its comorbidities, with a focus on bipolar disorder. J Affect Disord 2010;124:1-8.

19. Kessler RC, Adler L, Barkley R, Biederman J, Conners CK, Demler O, et al. The prevalence and correlates of adult ADHD in the United States: results from the National Comorbidity Survey Replication. Am J Psychiatry 2006;163:716-723.

20. Daigre Blanco C, Ramos-Quiroga JA, Valero S, Bosch R, Roncero C, Gonzalvo B, et al. Adult ADHD Self-Report Scale (ASRS-v1.1) symptom checklist in patients with substance use disorders. Actas Esp Psiquiatr 2009;37:299-305.

21. Simon V, Czobor P, Balint S, Meszaros A, Bitter I. Prevalence and correlates of adult attention-deficit hyperactivity disorder: meta-analysis. Br J Psychiatry 2009;194:204-211.

22. Das D, Cherbuin N, Butterworth P, Anstey KJ, Easteal S. A populationbased study of attention deficit/hyperactivity disorder symptoms and associated impairment in middle-aged adults. PLoS One 2012;7:e31500.

23. de Zwaan M, Gruss B, Muller A, Graap H, Martin A, Glaesmer H, et al. The estimated prevalence and correlates of adult ADHD in a German community sample. Eur Arch Psychiatry Clin Neurosci 2012;262:79-86.

24. Berry CA, Shaywitz SE, Shaywitz BA. Girls with attention deficit disorder: a silent minority? A report on behavioral and cognitive characteristics. Pediatrics 1985;76:801-809.

25. Rosler M, Retz W, Retz-Junginger P, Stieglitz RD, Kessler H, Reimherr F, et al. Attention deficit hyperactivity disorder in adults. Benchmarking diagnosis using the Wender-Reimherr adult rating scale. Nervenarzt 2008;79:320-327.

26. Jensen PS, Rubio-Stipec M, Canino G, Bird HR, Dulcan MK, SchwabStone ME, et al. Parent and child contributions to diagnosis of mental disorder: are both informants always necessary? J Am Acad Child Adolesc Psychiatry 1999;38:1569-1579.

27. Bron TI, Bijlenga D, Kasander MV, Spuijbroek AT, Beekman AT, Kooij JJ. Long-term relationship between methylphenidate and tobacco consumption and nicotine craving in adults with $\mathrm{ADHD}$ in a prospective cohort study. Eur Neuropsychopharmacol 2012 inpress.

28. Gittelman R, Mannuzza S, Shenker R, Bonagura N. Hyperactive boys almost grown up. I. Psychiatric status. Arch Gen Psychiatry 1985;42: 937-947.

29. Murphy P, Schachar R. Use of self-ratings in the assessment of symptoms of attention deficit hyperactivity disorder in adults. Am J Psychiatry 2000;157:1156-1159. 